\title{
A representação da cultura de consumo em Eles eram muitos cavalos, de Luiz Ruffato
}

Ligia Bezerra $^{1}$

O romance Eles eram muitos cavalos (2001), de Luiz Ruffato, tem sido foco de uma variedade de estudos, os quais têm explorado temas como a expressão do real (Schøllhammer, 2007), a representação da violência urbana (Lehnen, 2007) e da vida cotidiana (Sá, 2007), questões relativas à cidadania (Harrison, 2005), à cidade globalizada (Paula, 2014) e à modernidade (Rocha, 2012), para citar somente algumas abordagens. O presente trabalho apresenta uma contribuição aos estudos da narrativa em questão, com vistas a explorar a representação do consumo no romance. Argumentamos que Luiz Ruffato, ao inserir múltiplas referências a objetos de consumo como índices de realidade, enfatiza a presença constante e inescapável da cultura de consumo no dia a dia de grandes centros urbanos brasileiros como a cidade de São Paulo, onde se passa a narrativa. Tais referências a mercadorias aparecem no texto não como metáfora de uma força alienante que atua sobre consumidores irracionais de um determinado grupo social, mas, sim, como um marco de experiências de um número variado de indivíduos, criando identificações, bem como reforçando divisões sociais.

A seguir, apresentamos definições dos conceitos de cultura de consumo e de cotidiano, seguidas da análise de uma seleção de fragmentos de Eles eram muitos cavalos, doravante referido como EEMC. Foram selecionados fragmentos que fazem referência ao consumo de variados produtos, incluindo menções explícitas a marcas e bens culturais tornados mercadorias, tais como canções e objetos de arte.

\section{Cultura de consumo e cotidiano}

Revisando teorias sobre o consumo nos campos da economia, da sociologia e da psicologia em seu livro Consumer culture and postmodernism (2007), Mike Featherstone enfatiza a importância do foco nas práticas diárias de consumo, as quais, segundo ele, tendem a ficar

\footnotetext{
${ }^{1}$ Doutora em português e estudos culturais e professora do Departamento de Letras e Literaturas Estrangeiras de Spelman College, em Atlanta, Geórgia, Estados Unidos. Email: lbezerra@spelman.edu
} 
de fora de várias das análises empreendidas pelos campos em questão. Propondo um movimento para além da avaliação negativa dos desejos de consumo herdada da teoria sobre cultura de massas, Featherstone sugere que não tomemos como pressuposto que o consumo deriva direta e simplesmente da demanda criada por um problema de produção (Featherstone, 2007, p. 13). Em outras palavras, não consumimos apenas para sustentar uma produção que se nos impõe. Featherstone se junta a Mary Douglas e Baron Isherwood, os quais argumentam que o consumo é um ato social. A partir dessa perspectiva,

Uma teoria sobre o consumo tem que ser uma teoria da cultura e do gosto social. Separar a cultura de um sistema organizacional é boiar num oceano de relativismo. Se uma organização funciona bem, ela pode dotar objetos de valor; ser um objeto consumível significa ser um objeto capaz de circular como marcador de determinados conjuntos de papéis sociais (Douglas e Isherwood, 1996, p. xxii-iii, tradução nossa).

Dessa forma, o consumo pode ser visto não meramente como uma questão de racionalidade moral, mas, sim, como algo motivado por estruturas socioculturais que determinam - e contestam - limites sociais mais ou menos rigorosos. Podemos falar, assim, de uma cultura de consumo, ou seja, de uma arquitetura sociocultural que engendra nossos papéis de consumidores.

O teórico Néstor García Canclini também apresenta uma visão semelhante do termo consumo em Consumers and citizens (2001). Pare ele, o termo se refere ao "conjunto de processos socioculturais nos quais se dá a apropriação e o uso de produtos" (Canclini, 2001, p. 38, tradução nossa). Canclini defende que o consumo não diz respeito ao simples resultado de diferenças de gosto individual ou de reflexões críticas acerca do poder de compra de cada consumidor, mas a um processo no qual se deve levar em consideração as diferenças de classe social que se reproduzem também no momento em que esses bens são consumidos. Canclini ressalta, ainda, que o consumo não produz somente divisões sociais mas também formas de integração, na medida em que cria códigos de comunicação entre os indivíduos. Em outras palavras, a associação de certos produtos a significados simbólicos como sofisticado ou brega, por exemplo, é possível, porque os membros de uma mesma sociedade reconhecem tais significados. 
EEMC recorre ao reconhecimento desses valores por parte do leitor ao representar bens de consumo como signos da realidade cotidiana do Brasil atual. Em outras palavras, mercadorias específicas são introduzidas na narrativa como o que Karl Schøllhammer denomina de índices, cuja "inclusão literal funciona agora já não pela representação do conteúdo, mas pela presença dentro do contexto ficcional da escrita de uma parte da própria cidade" (Schøllhammer, 2009, p. 71). Ao elaborar essa denúncia através de índices de realidade, Ruffato evita apresentar julgamentos morais acerca dos hábitos de consumidores enquanto indivíduos. Seus personagens não são tomados como alienados por consumir ou querer consumir esta ou aquela mercadoria. Dessa forma, EEMC apresenta uma denúncia das injustiças e do caos social como algo que emerge, em grande parte, de um sistema socioeconômico que gera desigualdade de poder aquisitivo mediante as pressões de uma cultura de consumo que se manifesta diariamente como código social quase natural. Em EEMC, o ato/desejo de consumir é retratado como parte intrínseca do cotidiano da vida brasileira, presente no dia a dia de indivíduos de diferentes backgrounds socioculturais.

Assim sendo, a vida cotidiana é representada em EEMC da forma como define a pesquisadora Rita Felski em seu ensaio "The Invention of Everyday Life" (2000). Fazendo um apanhado de várias definições do termo no campo dos estudos culturais, a autora propõe que o cotidiano deve ser visto como

um conjunto de atividades circunscritas no mundo. A vida cotidiana é o simples processo de se tornar acostumando a suposições, comportamentos e práticas que se tornam evidentes em si mesmas e tidas como certas. Em outras palavras, a qualidade de ser cotidiano (everydayness) não é algo intrínseco que magicamente se adere a ações ou pessoas em particular (as mulheres, a classe trabalhadora). Do contrário, o ser cotidiano é um processo vivo de rotinização que todos indivíduos experimentam (Felski, 2000, p. 31, tradução nossa).

A vida cotidiana é central na obra de Ruffato em questão, como aponta Schøllhammer em sua análise do romance. ${ }^{2}$ Argumentamos que

\footnotetext{
${ }^{2} \mathrm{O}$ pesquisador em questão resume que EEMC retrata "as histórias ignotas do dia a dia de pessoas anônimas, sem brilho e sem reconhecimento, protagonistas da vida como ela é, da micro-história e de todos os pequenos dramas que só excepcionalmente emergem para a atenção pública" (Schøllhammer, 2009, p. 69).
} 
é também desde essa perspectiva do cotidiano que a cultura de consumo é tratada no texto. O efeito de cotidianidade, no sentido de que fala Rita Felski, ou seja, no sentido daquilo que passa a ser natural através da repetição, é alcançado na narrativa através da representação de bens materiais como índices de realidade, da forma como apontamos acima. Nesse sentido, EEMC ressalta a presença inescapável e quase natural da cultura de consumo no dia a dia das grandes cidades brasileiras, bem como os custos sociais dessa presença. Essa perspectiva cotidiana crítica da cultura de consumo colabora com a construção da imagem de uma São Paulo enquanto cidade globalizada, nos termos que descreve a pesquisadora Leonora Paula: um espaço predominantemente distópico, representado através de uma linguagem que posiciona o leitor como experimentador corpóreo das dissonâncias de tal espaço (Paula, 2014, p. 98). Como tal, o leitor se reconhece no cotidiano da cidade como consumidor em potencial ou efetivo dos bens mencionados, reconhecendo os significados sociais das práticas consumidoras corriqueiras nas quais ele se engaja, deseja engajar-se ou observa outros se engajarem. A seguir, analisamos vários fragmentos do livro com vistas a identificar como Ruffato representa diversos aspectos da vida cotidiana de grandes centros urbanos como a cidade de São Paulo, através de referências a objetos de consumo mencionados em vários momentos das micronarrativas do livro.

\section{Consumo cotidiano na metrópole}

EEMC reúne 69 fragmentos de texto que incluem descrições, pequenas narrativas, diálogos, monólogos, além de reproduções de textos, ao que tudo indica fictícios, tão variados quanto horóscopos, previsões do tempo e cartas escritas à mão. Como várias análises do romance já apontaram, embora cada fragmento possa ser lido independentemente e em qualquer ordem, os diferentes pedaços da narrativa estão conectados pelo fato de que todos se referem a um dia na cidade de São Paulo, como se indica logo no início do texto.

Praticamente todos esses fragmentos contêm alguma referência a bens de consumo materiais ou culturais reconhecíveis, sejam eles marcas, canções ou programas de televisão. Uma das funções desses bens de consumo enumerados ao longo da narrativa consiste em marcar a classe 
social dos personagens, denunciando como desigualdades sociais estão codificadas em padrões de consumo na sociedade brasileira atual.

Os hábitos de consumo da classe média podem ser identificados, por exemplo, nos fragmentos "A caminho", "Negócio", “Onde estávamos há cem anos" e "Nós poderíamos ter sido grandes amigos". O primeiro fragmento, "A caminho", inicia com a descrição de um carro importado que corre veloz pelas ruas de São Paulo, "ignorando" a irregularidade do asfalto. O luxo do carro, portanto, contrasta com a precariedade da estrada que ele percorre, deixando implícita uma crítica às disparidades econômicas de um país no qual o capital privado provê acesso a produtos caros importados, enquanto bens públicos não são mantidos da maneira devida. Mais à frente no fragmento, descreve-se um homem cujo status social é evidenciado pelas marcas que ele consome: "camisa Giorgio Armani, perfume Polo borrifado no pescoço, sapatos italianos, escanhoado, cabelo à-máquina-dois, Rolex de ouro sob o tapete" (Ruffato, 2007, p. 14). Semelhante status social dos personagens também é mostrado no fragmento "Negócio" através da menção de marcas e atividades que têm certo prestígio na sociedade brasileira. Nesse fragmento, um pai dirige uma Mercedes em direção a um McDonald's, onde ele irá celebrar o aniversário de 12 anos do filho com um Big Mac, nuggets com molho barbecue e uma Coca-Cola light.

Em ambos os fragmentos mencionados acima, personagens sem nome são definidos primariamente pelos bens que consomem, como a indicar que eles são o que consomem, ou seja, que os bens materiais do indivíduo importam mais que sua história de vida. Possuir um carro importado, usar roupas de certa marca, comer no McDonald's atividade que no Brasil se associa com certo prestígio social devido ao preço da comida dessa cadeia de restaurantes no país e à sua associação com a cultura americana - são signos do real que, em si mesmos, condensam um modo de viver imediatamente reconhecível ao leitor conhecedor do status de tais produtos no estilo de vida da classe média.

Um estilo de vida sofisticado e culto também é traduzido em mercadorias consumidas pelos personagens em “Onde estávamos há cem anos?" O fragmento inicia com o personagem dirigindo um Honda Civic em direção ao aeroporto, onde embarcará para Miami. Além da viagem aos Estados Unidos, em particular a uma das mecas de consumo na imaginação brasileira, o narrador também aponta como indício do status social do personagem o fato de ele estar ouvindo Betty Carter, 
cantora americana de jazz. A música de Carter nesse contexto serve para encapsular uma ideia de sofisticação na medida em que o jazz americano é visto como música sofisticada, comumente consumida por uma classe social mais abastada que, via de regra, possui um grau de instrução relativamente alto. $\mathrm{O}$ ambiente de conforto criado pela música de Carter contrasta com o mundo fora do veículo que o personagem dirige, do qual ele tenta escapar ao aumentar o volume do som do carro e ao lembrar-se de uma viagem à Itália. Lá fora, segundo a voz narrativa, meninos pedem esmolas, meninas sujas carregam bebês, adolescentes se prostituem e gatos e crianças dividem o espaço de prédios abandonados (Ruffato, 2007, p. 86). Assim sendo, a menção de marcas e as referências a objetos culturais considerados sofisticados geram um profundo contraste com o mundo ao redor do personagem, no qual é exatamente a ausência do consumo, ou o consumo de restos, que impera. O personagem, no entanto, segue sua jornada ignorando esse contraste, indicando o quão banais são para ele essas diferenças de consumo que se traduzem em divisões sociais.

Também em "Nós poderíamos ter sido grandes amigos", objetos de consumo aparecem como marca do status social da classe média. No fragmento, o personagem-narrador imagina como teria sido sua relação com um vizinho que foi recentemente sequestrado e morto, revelação que só aparece ao final do fragmento de modo passageiro e banal. Os objetos consumidos pelo personagem-narrador e seus amigos incluem objetos culturais tornados mercadoria tais como a música de Chico Buarque e de Dinah Washington, ou obras surrealistas reproduzidas em um avental. Diante da passageira referência ao destino final do vizinho, tais mercadorias ocupam maior espaço físico na narrativa que a violência sofrida por ele. A importância do objeto de valor em comparação com a vida humana fica ainda mais clara ao final do trecho, quando o narrador indica: "O corpo foi encontrado hoje de manhã. O carro ainda não" (Ruffato, 2007, p. 49). Nessas duas frases, curtas e de sintaxe simples, está condensada a lógica de um capitalismo predador, o qual produz disparidades sociais capazes de gerar situações nas quais bens de consumo adquirem um valor mais alto que o da vida humana. Em outras palavras, é do contraste entre a banalidade com a qual a revelação da morte do vizinho é feita e a ênfase nos objetos de consumo mencionados que se produz o impacto da constatação de que a violência se tornou algo banal nos grandes centros urbanos brasileiros e que a vida humana 
importa menos que os produtos consumidos por aquela vida. Estilisticamente, esse impacto é provocado pela suspensão do narrado e pela economia de descrições que acarretam o efeito de real da narrativa de que fala Levy em sua análise do romance (Levy, 2003, p. 181).

Enquanto fragmentos como os acima analisados focalizam os objetos de consumo da classe média brasileira, outros fragmentos retratam objetos de consumo das classes populares. Esse é o caso de "Uma copa", no qual o narrador apresenta uma lista de objetos encontrados na copa da casa de uma mulher "que sai na agonia da madrugada para trabalhar" (Ruffato, 2007, p. 69). Os objetos incluem desde "uma batedeira Walita de raro uso" a "um scotch whisky White Horse (falsificado)" (Ruffato, 2007, p. 70-71). Enquanto marcas como Panasonic, Philips e Walita indicam certo poder aquisitivo, objetos de gesso, uma réplica de um quadro de Renoir e uma coleção de CDs de cantores e grupos populares - como a dupla dos anos 1980-1990 Jairzinho e Simony, os grupos de pagode Raça Negra e Grupo Molejo ou, ainda, a dupla sertaneja Leandro e Leonardo e a trilha sonora internacional de uma novela da maior rede de televisão do país, Dono do mundo - apontam para o gosto popular dos(as) donos(as) desses objetos. Ao indicar a difícil rotina da dona da casa, bem como o consumo de cópias de objetos caros cujos originais somente as classes de maior poder aquisitivo podem adquirir, o narrador aponta a desigualdade de acesso a bens materiais por parte de diferentes membros da sociedade. Indica, além disso, as estratégias de consumo da classe trabalhadora, que recria os códigos de consumo da classe média dentro dos limites da sua condição socioeconômica.

De forma similar a "Uma copa", o fragmento "Uma estante" também consiste em uma lista objetos de consumo. Nesse caso, são livros de autores populares como Paulo Coelho, clássicos como Graciliano Ramos, estrangeiros como Stendhal, além de livros de autoajuda com títulos como "Ajuda-te pela psiquiatria" e alguns livros sobre marketing. A heterogeneidade dessa estante, assim descrita sem nenhuma outra informação sobre o(s) seus(s) possíveis leitores, chama a atenção pelo fato de condensar leituras que seriam consideradas tanto da baixa como da alta cultura, nivelando, dessa forma, esses dois polos. Os fragmentos "Uma copa" e "Uma estante" sugerem que o consumo das culturas ditas alta e baixa pode perpassar uma mesma classe social. Certos objetos de consumo, como o quadro de Renoir (falsificado ou não), possuem um significado comum de sofisticação para classes sociais 
diferentes; enquanto o gosto popular representado, por exemplo, pelos livros de Paulo Coelho, é incorporado à cultura hegemônica. Esse nivelamento da alta e da baixa culturas, realizado através de uma linguagem experimental que permeia o livro como um todo, continua uma tradição de experimentação linguística através de referências à cultura de massas, a qual tem estado presente na literatura brasileira desde o modernismo e é recuperada entre os anos 1960 e 1980 por autores como Clarice Lispector e Sérgio Sant'Anna (Santos, 2006), ressurgindo na virada do século XXI (Bezerra, 2015).

Ao utilizar um vocabulário associado à mídia (zapear, flashes, zoom etc.) em suas análises de EEMC, críticos como Nelson Vieira, Tatiana Salem Levy, Giovanni Ricciardi, Cecília Almeida Salles e Maria Zilda Cury, entre outros, sugerem que esse romance estabelece um diálogo com a linguagem da mídia. Embora Schøllhammer, em "Fragmentos do real e o real do fragmento", argumente contra tal percepção de que a linguagem de EEMC imite a da cultura de massas, acreditamos que o próprio fato de a obra em questão permitir comparações como as descritas acima indica que EEMC, se não procura reproduzir tal linguagem, no mínimo vai ao encontro de uma sensibilidade de um leitor contemporâneo cujo olhar se revela acostumado a visualizar tais técnicas narrativas como relacionadas à sintaxe midiática. Trata-se, a nosso ver, de uma resposta experimental com a linguagem da mídia àquela questão que Schøllhammer afirma ser uma das principais que a literatura brasileira escrita desde os anos 1990 tenta responder: a de como retratar o real "diante de um pano de fundo midiático caracterizado por uma grande demanda de realidade" (Schøllhammer, 2009, p. 56).

Outro exemplo do consumo que perpassa camadas sociais de níveis distintos nas atividades mais banais do dia a dia aparece em fragmentos como "De branco", em que um médico liga a televisão para ouvir o barulho dela ao descansar, e em "A menina", no qual uma criança de 8 anos, filha de uma empregada doméstica e de um técnico de arcondicionado, assiste à televisão enquanto come e ouve o rádio enquanto lava roupa. Assim sendo, a cultura de massas aparece em EEMC não somente na condição de objeto de manipulação de um segmento social específico, como sugerem vários teóricos da cultura de massas (Featherstone, 2007), mas também assume funções como simplesmente servir de companhia ou distração durante ou depois de um dia de trabalho. No entanto, se o consumo da cultura de massas pelos dois 
personagens em questão parece ser o mesmo, as condições nas quais se dá esse consumo com certeza não coincidem: enquanto no primeiro caso temos um adulto em uma posição de prestígio social que the rende uma quantia significativa de dinheiro, no segundo caso, temos o retrato da triste realidade de crianças que precisam trabalhar em afazeres domésticos os mais diversos devido a sua condição socioeconômica.

Dificuldades de acesso a sonhados bens de consumo são também retratadas em vários fragmentos de EEMC. É o caso, por exemplo, de "Brabeza", no qual acompanhamos os pensamentos de um jovem que planeja como vai conseguir dinheiro para comprar um presente do Dia das Mães para a mãe doente. $O$ fragmento inicia com o personagem descrevendo o objeto desejado: um rádio gravador $\mathrm{AM} / \mathrm{FM} \mathrm{CCE}$, que serviria de substituto ao que ele de fato gostaria de adquirir, "uma televisão Toshiba, vinte polegadas, som estéreo, vídeo embutido" (Ruffato 2007, p. 44). O personagem ressalta que a escolha do gravador no lugar da televisão deve-se ao custo mais alto desta, impossível de se pagar, mesmo à prestação, devido às exigências de documentos e comprovantes de renda que ele não possui. Desempregado, o personagem não vê outra solução para conseguir o presente da mãe a não ser assaltar alguém. O que segue a decisão com respeito ao assalto é a elaboração de um plano: o personagem reflete sobre porque assaltar uma mulher e não um homem, que tipo físico de homem escolher caso assaltar uma mulher não seja possível, e em que lugar procurar "quem vai financiar o rádio AM/FM CCE estéreo da dona Chiquinha" (Ruffato, 2007, p. 46). Assim sendo, o desejo de consumo impossibilitado pela falta de recursos financeiros leva o personagem a encontrar outros meios de adquirir o produto que ele almeja através do que se poderia chamar, na perspectiva da pessoa assaltada, de um ato de violência. Tal representação da violência, pela perspectiva do "agressor" e não da "vítima", expõe a forma como o primeiro é também vítima de um sistema socioeconômico que gera desemprego, juntamente com uma cultura capitalista que vende sonhos de consumo que não estão ao alcance de todos. Assim sendo, como aponta o pesquisador Nelson Vieira, EEMC representa

os espaços vividos pelos necessitados, desapossados de uma cidadania autêntica, mas [que] mesmo assim lutam para o seu espaço. O romance ilustra este espaço como "diferencial" com os seus modos de operar e as suas táticas para desafiar o status quo 
espacial na esperança de atingir o seu lugar ao sol. Porém, sendo diferencial este lugar pode temporariamente pertencer a eles, mas este espaço precário não significa um pertencimento cidadão, e sim um pertencimento periférico (Vieira, 2007, p. 130).

Pertencimento periférico é também o caso, por exemplo, dos personagens de “De cor". Nesse fragmento, pai e filho fazem o percurso até o ponto onde vendem cachorro-quente. No caminho, encontram um rapaz que passa a acompanhá-los e para quem revelam o talento do menino, o qual é capaz de dizer em que estado fica qualquer cidade do país. Mostrando-se impressionado com a inteligência do menino, o rapaz sugere que o homem o leve a um programa de televisão para que o talento do menino seja recompensado financeiramente. $\mathrm{O}$ conto termina com a palavra "televisão" em itálico, seguida de reticências, como a sugerir que o homem repete para si mesmo a sugestão do rapaz, sonhando com a possibilidade de conseguir algum alívio financeiro imediato que só o meio de comunicação de massa em questão parece ser capaz de lhe proporcionar diante da falta de assistência do governo e das dificuldades que ele enfrenta por trabalhar no setor informal. Essa situação financeira precária promete repetir-se no futuro do menino. Este, apesar de sua facilidade para aprender, teve que abandonar a escola para ajudar o pai e sonha agora em um dia poder deixar a venda de cachorro-quente para ser caminhoneiro.

EEMC termina, como aponta a pesquisadora Leila Lehnen, de forma a enfatizar o esfacelamento geográfico, social e epistemológico do espaço urbano (Lehnen, 2007, p. 88). Como temos visto até aqui, o consumo tem um papel importante nesse esfacelamento. Os três últimos fragmentos do livro - "Cardápio', duas páginas com dois quadros negros, e um último fragmento sem título, que consiste de um diálogo entre um homem e uma mulher - podem ser interpretados como complementares a partir da perspectiva da representação do consumo que propomos na presente análise. O primeiro dos três fragmentos, "Cardápio", é literalmente o que o título descreve: um cardápio que contém seções de coquetel, entrada, prato principal e sobremesa. Cada uma das seções em questão possui itens como "damasco com queijo gruyère e nozes", "salmão defumado com panqueca", e "torta de marzipã e chocolate" (Ruffato, 2007, p. 153-154). Os pratos, como indicam os ingredientes em suas descrições, são requintados e caros e, portanto, a serem consumidos por aqueles de maior poder aquisitivo. 
Em contraposição ao excesso representado no cardápio está a escassez não só de comida, mas de direitos de cidadão - representada por dois retângulos pretos que aparecem consecutivos ao cardápio. Esse contraste entre o excesso e a falta gera a violência que volta a aparecer no último fragmento da narrativa, o qual é subsequente às páginas com os retângulos pretos. Assim sendo, a sequência dos fragmentos sugere uma conexão entre a cultura de consumo e a produção da violência na sociedade brasileira do século XXI.

\section{Reflexões finais}

EEMC representa a complexidade do consumo de bens culturais na vida cotidiana brasileira. Como aponta Lúcia Sá, em EEMC "praticamente não existem descrições de massas. A ideia da cidade, da sua enormidade, é dada pela multiplicação de histórias individuais histórias diferentes que podem potencialmente se multiplicar ao infinito, como a própria cidade" (Sá, 2007, p. 94). Por um lado, ao retratar as experiências cotidianas de consumo de forma individual e não coletiva, EEMC ressalta a heterogeneidade da população urbana, contestando, portanto, a ideia da existência de um massa homogênea de indivíduos de uma certa classe social manipulados por um poder soberano e totalizante. Por outro lado, essa ênfase na história individual, nos acontecimentos banais e dispersos em um dia na cidade de São Paulo traduz para a literatura o que, em Liquid Times (2007), Zygmunt Bauman chama de uma "utopia de caçadores". Para o autor, no mundo contemporâneo, encontramos o discurso de sobrevivência individual por meio do consumo, em vez do discurso moderno de progresso coletivo (Bauman, 2007, p. 103). Em EEMC, todos se movimentam pela cidade, leem a realidade a seu redor e se relacionam com ela através de alguma forma de consumo, sem nenhuma indicação de um futuro que contemple um projeto coletivo. Também o leitor é interpelado como consumidor na medida em que lhe são apresentadas referências a marcas, programas de televisão, música pop etc., como índices de realidade com seus significados sociais tidos como quase naturais. A narrativa de Ruffato em questão, no seu tom experimental e no diálogo que estabelece com a cultura de consumo, busca uma forma de expressão na literatura para essa "utopia de caçadores". 


\section{Referências}

BAUMAN, Zygmunt (2007). Liquid times. Living in the Age of Uncertainty. Malden: Polity Press.

BEZERRA, Ligia (2015). Everyday life in the McOndo and McUnaima worlds: mass culture in twenty-first century Brazilian and Argentine fiction. Diss. Indiana University.

CANCLINI, Néstor García (2001). Consumers as citizens. Globalization and multicultural conflicts. Tradução de George Yúdice. Minneapolis: Minnesota UP.

CURY, Maria Zilda Ferreira (2007). Ética e simpatia: O olhar do narrador em contos de Luiz Ruffato. In: HARRISON, Marguerite Itamar. Uma cidade em camadas: ensaios sobre o romance Eles eram muitos cavalos, de Luiz Ruffato. Vinhedo: Horizonte, p. 107-18.

DOUGLAS, Mary; ISHERWOOD, Baron (1996). The world of goods. New York: Routledge.

FEATHERSTONE, Mike (2007). Consumer culture ad postmodernity. Sage: Londres.

FELSKI, Rita (2000). The invention of everyday life. New Formations, London, n. 39 , p. 15-31.

HARRISON, Marguerite Itamar (2005). "São Paulo lightning": flashes of a city in Luiz Ruffato's Eles eram muitos cavalos. Luso-Brazilian Review, Madison, v. 42, n. 2, p. 150-164.

HARRISON, Marguerite Itamar (Ed.) (2007). Uma cidade em camadas: ensaios sobre o romance Eles eram muitos cavalos, de Luiz Ruffato. Vinhedo: Horizonte.

LEHNEN, Leila (2007). Os não-espaços da metrópole: espaço urbano e violência social em Eles eram muitos cavalos. In: HARRISON, Marguerite Itamar. Uma cidade em camadas: ensaios sobre o romance Eles eram muitos cavalos, de Luiz Ruffato. Vinhedo: Horizonte, 207, p. 77-91.

LEVY, Tatiana Salem (2003). O silêncio da representação: uma leitura de Eles eram muitos cavalos. Estudos de Literatura Brasileira Contemporânea, Brasília, n 22, jan.-jul., p. 173-184.

PAULA, Leonora (2014). Eles eram muitos cavalos: challenging the regulating fiction of the global city. Romance Notes, Chapel Hill, v. 54, n. 1, p. 95-102.

RICCIARDI, Giovanni (2007). Perdas para um mosaico. In: HARRISON, Marguerite Itamar. Uma cidade em camadas: ensaios sobre o romance Eles eram muitos cavalos, de Luiz Ruffato. Vinhedo: Horizonte, p. 48-52. 
ROCHA, Rejane Cristina (2012). As formas do real: a representação da cidade em Eles eran muitos cavalos. Estudos de Literatura Brasileira Contemporânea, Brasília, n. 39, jan.-jun., p. 107-127.

RUFFATO, Luiz (2007). Eles eram muitos cavalos. São Paulo: Record.

SÁ, Lúcia (2007). Dividir, multiplicar, repetir: A São Paulo de Luiz Ruffato. In: HARRISON, Marguerite Itamar. Uma cidade em camadas: ensaios sobre o romance Eles eram muitos cavalos, de Luiz Ruffato. Vinhedo: Horizonte, p. 92-101.

SALLES, Cecilia Almeida (2007). Um 9 de maio qualquer. In: HARRISON, Marguerite Itamar. Uma cidade em camadas: ensaios sobre o romance Eles eram muitos cavalos, de Luiz Ruffato. Vinhedo: Horizonte, p. 43-7.

SANTOS, Lidia (2006). Tropical kitsch: media in Latin American literature and art. Tradução de Elisabeth Enenbach. Princeton: Markus Weiner.

SCHØLLHAMMER, Karl Erik (2007). Fragmentos do real e o real do fragmento. In: HARRISON, Marguerite Itamar. Uma cidade em camadas: ensaios sobre o romance Eles eram muitos cavalos, de Luiz Ruffato. Vinhedo: Horizonte, p. 68-76.

SCHØLLHAMMER, Karl Erik (2009). Ficção brasileira contemporânea. Rio de Janeiro: Civilização Brasileira.

VIEIRA, Nelson H. (2007). O desafio do urbanismo diferencial no romance de Luiz Ruffato: Espaço, práxis e vivência social. In: HARRISON, Marguerite Itamar. Uma cidade em camadas: ensaios sobre o romance Eles eram muitos cavalos, de Luiz Ruffato. Vinhedo: Horizonte, p. 119-29.

Recebido em março de 2015.

Aprovado em setembro de 2015.

\section{resumo/abstract/resumen}

\section{A representação da cultura de consumo em Eles eram muitos cavalos, de Luiz Ruffato}

Ligia Bezerra

Este artigo apresenta uma análise da representação do consumo em Eles eram muitos cavalos, do escritor Luiz Ruffato. Argumentamos que o autor, através da inserção de referências a objetos de consumo como índices de realidade, enfatiza a presença constante e inescapável da cultura de consumo no dia a dia de grandes centros urbanos brasileiros. Utilizando contribuições dos estudos culturais para o estudo da cultura de consumo e do cotidiano, mostramos que 
essas referências aparecem no texto não como metáfora de uma força alienante que atua sobre consumidores irracionais de um determinado grupo social, mas, sim, como um marco de experiências de um número variado de indivíduos, criando identificações, bem como reforçando divisões sociais.

Palavras-chave: consumo, cotidiano, espaço urbano, Luiz Ruffato.

\section{The representation of consumer culture in Luiz Ruffato's Eles eram muitos cavalos}

\section{Ligia Bezerra}

This article analyzes the representation of consumption in Luiz Ruffato's Eles eram muitos cavalos. I argue that the writer, by referencing commodities as tokens of reality, emphasizes the inescapable presence of consumer culture in the everyday life of large urban centers in Brazil. Utilizing cultural studies' theoretical contributions to the study of consumption and everyday life, I demonstrate that these references, rather than appearing as a metaphor for an alienating force controlling irrational consumers from a certain social segment, appear in Ruffato's text as part of the experience of various social segments, creating identifications among its members, as well as reinforcing social divisions.

Keywords: consumption, everyday life, urban space, Luiz Ruffato.

\section{La representación de la cultura de consumo en Eles eram muitos cavalos, de Luiz Ruffato}

Ligia Bezerra

En este artículo se analiza la representación del consumo en Eles eram muitos cavalos, del escritor Luiz Ruffato. Argumentamos que el autor, mediante el uso de referencias a objetos de consumo como índices de realidad, enfatiza la presencia constante e inescapable de la cultura de consumo en la cotidianidad de los grandes centros urbanos brasileros. Utilizando las contribuciones de los estudios culturales para el estudio de la cultura de consumo y de lo cotidiano, demostramos que estas referencias aparecen en el texto no como metáfora de una fuerza alienante que actúa sobre los consumidores irracionales de un determinado grupo social, sino como una marco de experiencias de un número variado de individuos, creando identificaciones así como reforzando divisiones sociales.

Palabras clave: consumo, cotidiano, espacio urbano, Luiz Ruffato. 